CLINICAL STUDY

\title{
Linear growth and intellectual outcome in children with long-term idiopathic subclinical hypothyroidism
}

\author{
Manuela Cerbone, Carmela Bravaccio, Donatella Capalbo, Miriam Polizzi ${ }^{1}$, Malgorazata Wasniewska ${ }^{2}$, \\ Daniela Cioffi, Nicola Improda, Mariella Valenzise ${ }^{2}$, Dario Bruzzese ${ }^{3}$, Filippo De Luca ${ }^{2}$ and Mariacarolina Salerno \\ Department of Pediatrics, University of Naples 'Federico II', Via S. Pansini 5, 80131 Naples, Italy, ${ }^{1}$ Department of Psychiatry and Child Neuropsychiatry, \\ 'Seconda Università' of Naples, 80131 Naples, Italy, ${ }^{2}$ Department of Pediatrics, University of Messina, 98124 Messina, Italy and ${ }^{3}$ Section of Medical \\ Statistics and Informatics, Department of Preventive Medical Sciences, University 'Federico II', 80131 Naples, Italy \\ (Correspondence should be addressed to M Salerno; Email: salerno@unina.it)
}

\begin{abstract}
Objective: The treatment of children with subclinical hypothyroidism (SH) is controversial for TSH values between 4.5 and $10 \mathrm{mU} / \mathrm{l}$. The aim of this cross-sectional, controlled study was to evaluate growth and intellectual outcome in children with persistent $\mathrm{SH}$ who have never been treated with levothyroxine.

Design and methods: Clinical and auxological parameters, thyroid function, and intellectual outcome were evaluated in 36 children with persistent SH at the age of 9.7 \pm 0.6 (range 4-18.0) years. Children had been followed longitudinally for 3.3 \pm 0.3 (range 2.0-9.3) years, from first diagnosis of SH until enrollment in the study. Thirty-six age- and sex-matched children were enrolled in the study as controls.

Results: At study entry, height ( $-0.8 \pm 0.2$ SDS), bone age/chronological age (BA/CA ratio 0.92 \pm 0.6 ), and body mass index (BMI $-0.1 \pm 0.2$ SDS) in SH children were normal. Despite long-term duration of $\mathrm{SH}$, none of these parameters showed a worsening with respect to height $(-0.7 \pm 0.2$ SDS), BA/CA $(0.97 \pm 0.03)$, and BMI $(-0.1 \pm 0.2)$ at the time of first SH detection. None of the children showed overt signs or symptoms of hypothyroidism during the follow-up.

Verbal $(99.1 \pm 2.2)$, performance (100.4 \pm 1.9$)$, and full-scale (99.7 \pm 1.9$)$ intelligence quotient (IQ) scores in SH children were normal and comparable to those of controls. No relationship was detected between IQ scores and the degree or duration of SH.

Conclusions: Persistent SH in children is not associated with alterations in growth, bone maturation, $\mathrm{BMI}$, and cognitive function or other complaints that could be ascribed to SH even after several years without therapeutic intervention.
\end{abstract}

European Journal of Endocrinology 164 591-597

\section{Introduction}

Subclinical hypothyroidism (SH), a biochemical condition characterized by increased serum levels of TSH with normal concentrations of thyroid hormones, is quite common in adults, with a prevalence ranging from 4 to $10 \%$ (1). There is a great controversy concerning the clinical significance of SH and whether or when subjects with SH should be treated with levothyroxine $\left(\mathrm{L}-\mathrm{T}_{4}\right)(2,3)$. In adults, $\mathrm{SH}$ has been associated with several complications such as progression into overt hypothyroidism, abnormalities in lipid profile, increased risk of atherosclerosis and cardiovascular morbidity, and clinical symptoms or signs of mild disease including impaired cognitive function $(1,4-8)$. Treatment is currently recommended in SH subjects with TSH value above $10 \mathrm{mU} / \mathrm{l}$, whereas treatment for TSH levels between 4.5 and $10 \mathrm{mU} / \mathrm{l}$ remains a matter of debate (1-3).
In children, SH is not yet a well-defined condition due to both the low prevalence of this disorder (9) and the lack of long-term studies. However, in children, SH seems to be a benign remitting condition with a low risk of progression to overt hypothyroidism $(10,11)$. In childhood, thyroid hormones play a crucial role in regulating growth, puberty, and body metabolism. Short stature and bone age (BA) retardation are the most well-known clinical signs of untreated overt hypothyroidism, but the effects of SH on growth and bone maturation are not well defined. In a recent multicenter Italian study on 92 children with idiopathic SH, stature was within normal limits at diagnosis and remained normal after 2 years of follow-up (11).

Thyroid hormones are also essential for the normal function and maturation of the $\mathrm{CN}$, and their absence during a critical period of development profoundly compromises cognitive functions. In children with congenital hypothyroidism who receive substitutive 
$\mathrm{L}_{-} \mathrm{T}_{4}$ treatment within the first weeks of life, a rapid normalization of TSH levels seems to be associated with a higher intelligence quotient (IQ) later in life. Furthermore, poor compliance to the therapy, documented by increased levels of TSH in the presence of normal levels of thyroid hormone, has been associated with lower intellectual performance and decreased visual-spatial ability (12).

As for adults, treatment of children with TSH of 4.5$10 \mathrm{mU} / \mathrm{l}$ is currently controversial. Therefore, we designed this cross-sectional controlled study aiming to evaluate whether persistent $\mathrm{SH}$ in a pediatric population may affect growth, BA maturation, body mass index (BMI), and intellectual outcome.

\section{Patients and methods}

\section{Study population}

The original cohort consisted of 47 Caucasian children (25 males), aged between 4.0 and 18.0 years, who had been referred to our centers for isolated and mild TSH elevation. Of the 47 children, 11 (23\%) normalized their TSH concentrations during the first 2 years of follow-up and were not taken into consideration for this study. Therefore, the study population consisted of 36 children (19 males) aged 9.7 \pm 0.6 (range 4.0-18.0) years who fulfilled the following inclusion criteria: i) TSH values $>4.2 \mathrm{mU} / \mathrm{l}$ (that is the upper limit of our reference range) up to a conventional limit of $10 \mathrm{mU} / \mathrm{l}$ with free thyroxine $\left(\mathrm{FT}_{4}\right)$ values within the reference range at the time of SH identification; ii) persistence of a similar biochemical pattern of $\mathrm{SH}$ for at least 2 years during the period that preceded this study; iii) absence of antithyroglobulin ( $\mathrm{Tg}-\mathrm{Ab})$ and anti-thyroperoxidase antibodies (TPO-Ab), normal echogenicity of the parenchyma on thyroid ultrasound, and absence of palpable goiter or symptoms related to hypothyroidism both at the time of SH identification and at the time of this study; iv) adequate urinary iodine excretion.

At the time of SH detection, all children had been sent to our clinics by their family pediatricians. In 22/36 SH children, thyroid function measurement had been part of a diagnostic work-up suggested for the following reasons: i) short stature in eight cases; ii) obesity in three cases; iii) overweight in six other cases; iv) familial history of thyroid diseases and/or other autoimmune diseases in five cases. In the remaining 14 cases, TSH measurement had been performed in the context of a periodical check-up. From first observation of $\mathrm{SH}$ until the time of this study, all children were periodically followed in our centers. None of them had ever been treated with $\mathrm{L}_{-} \mathrm{T}_{4}$.

As for the 11 children who normalized their TSH $(\leq 4.2 \mathrm{mU} / \mathrm{I})$, the reasons for measuring $\mathrm{TSH}$ were similar to those of the study population: i) short stature in two cases; ii) obesity in two cases; iii) overweight in one case; iv) familial history of thyroid diseases and/or other autoimmune diseases in three cases; v) a periodical check-up in the remaining three cases.

\section{Controls}

Thirty-six healthy euthyroid children who had undergone a periodical check-up that included also TSH measurement were enrolled in this study as controls according to a cooperative study program between our centers and the family pediatricians. These children were matched for age, sex, pubertal, and socioeconomic status (SES). All of them were from the same geographic region of the children with $\mathrm{SH}$.

Overall, in 50/72 children included in this study (14 SH children and 36 controls), the common reason of measuring TSH was a screening program.

\section{Study protocol}

At study entry, all subjects (SH children and controls) underwent clinical examination; height, weight, fasting $\mathrm{TSH}, \mathrm{FT}_{4}, \mathrm{Tg}, \mathrm{Tg}-\mathrm{Ab}, \mathrm{TPO}-\mathrm{Ab}$, insulin-like growth factor 1 (IGF1), urinary iodine excretion measurements; BA assessment; and intellectual evaluation. Thyroid ultrasound at study entry was performed only in children with SH.

Clinical examination was focused on ascertaining the existence of symptoms and/or signs of hypothyroidism. Bone maturation was evaluated using the Greulich and Pyle Atlas (13) and was expressed as BA/chronological age (CA) ratio. Parental height was measured at study entry, and target height (TH) was calculated according to Tanner et al. (14). The degree of adiposity was expressed as BMI $\left(\mathrm{kg} / \mathrm{m}^{2}\right)$. Height, TH, and BMI were all normalized by age and sex in accordance with Italian standards (15) and expressed as SDS.

In children with $\mathrm{SH}$, clinical, hormonal and BA evaluation, and thyroid ultrasound had also been performed at the time of $\mathrm{SH}$ detection.

In SH children with short stature (height $<-2$ SDS), a complete hormonal work-up, including GH stimulation test, was performed.

Informed parental consent for participation in the study was obtained for SH children and controls.

\section{Biochemical parameters}

$\mathrm{TSH}, \mathrm{FT}_{4}$, Tg, Tg-Ab, and TPO-Ab serum concentrations were measured by electrochemiluminescence immunoassay (ECLIA) using a commercial kit (Elecsys e cobas e. Roche Diagnostics) (reference ranges: TSH, 0.3-4.2 mU/l; $\mathrm{FT}_{4}, 9-26 \mathrm{pmol} / \mathrm{l} ; \mathrm{Tg}, 0-50 \mathrm{ng} / \mathrm{ml}$; Tg-Ab, 0-115; TPO-Ab, 0-34 mIU/l). Serum IGF1 levels were measured using a two-site IRMA kit (Diagnostics System Laboratories, Inc., Webster, TX, USA). The IGF1 intra- and inter-assay coefficients of 
variation (CV) were 3.4 and $8.2 \%$ respectively. The values obtained were standardized by age and sex, and expressed in SDS. Urine iodine levels were analyzed with an automated system (Autoanalyzer 3 system, Bran +Luebbe GmbH, Nordestedt, Germany) (reference range: $100-200 \mu \mathrm{g} / \mathrm{l})$.

\section{Intellectual evaluation}

IQ, in SH children and controls, was evaluated using one of three age-appropriate cognitive tests. Subjects aged between 4 and 6 years received the wechsler preschool and primary scale of intelligence (WPPSI), those aged between 6 and 16 years were administered the wechsler intelligence scale for children, third edition (WISC III), and those over 16 years of age underwent the wechsler adult intelligence scale-revised (WAIS-R). These tests provide verbal IQ (VIQ), performance IQ (PIQ), and full-scale IQ (FSIQ) scores. The VIQ section includes six subtests (information, similarities, arithmetic, vocabulary, comprehension, and digit span) that measure general knowledge, language, reasoning, and memory skills. The PIQ section includes six subtests (picture completion, coding, picture arrangement, block design, object assembly, and mazes) that measure spatial, sequencing, and problem-solving skills. Normal IQ score was considered to be between 80 and 115 , with scale scores for each subtest having a mean of 10 and S.D. of 3 (range 1-19). An IQ score between 80 and 90 was considered to be low-normal. In each center, the IQ evaluation was carried out by a psychologist who was blinded with regard to the child's group (SH or control).

The children's psychological development was assessed by parental response on the age-appropriate child behavior checklist (CBCL), which focused on the children's behavioral and emotional problems during the previous 6 months. The CBCL includes eight domains of behavior: socially withdrawn, somatic complaints, anxious/depressed, social problems, thought problems, attention problems, delinquency, and aggressive behavior. Row scores were transformed into age- and gender-corrected T-norms using the Assessment Data Manager Software. A higher score indicates a greater number or intensity of behavior problems.

The Children's Depression Inventory (CDI) questionnaire, which was completed by the child, was used to evaluate the depression degree in children older than 7 years.

\section{Socioeconomic status}

SES was evaluated using the Graffar score revised, an index that classifies the education and occupation of each parent into five socioeconomic levels. A score of 1 reflects the highest SES occupation and education, and a score of 5 represents the lowest one.

\section{Statistical analysis}

All data are expressed as mean \pm s.e.m. KolmogorovSmirnov non-parametric procedure was used to confirm the normality distribution assumption for all quantitative variables. In case of normally distributed data, mean differences between groups were assessed using T-test for unpaired sample or using the Welch corrected T-test if the Levene statistic revealed heteroscedasticity. In case of non-normally distributed data, the MannWhitney non-parametric procedure was adopted.

Mean changes inside the $\mathrm{SH}$ group were assessed using the T-test for paired samples. In this case, the normality distribution assumption for the differences of values was also verified before applying the procedure. Pearson's correlation coefficient was used to evaluate the relationship between variables. All tests were two tailed, and values of $P<0.01$ were considered significant. Statistical analysis was performed using SPSS (Chicago, IL, USA).

\section{Results}

\section{Clinical and hormonal parameters}

Clinical and hormonal findings at study entry in children with $\mathrm{SH}$ and in the control group are reported in Table 1. TSH values ranged from 4.5 to $10.0 \mathrm{mU} / \mathrm{l}$ in children with $\mathrm{SH}$ and from 1.3 to $4.1 \mathrm{mU} / \mathrm{l}$ in the control group.

At study entry, mean height in children with $\mathrm{SH}$ was normal $(-0.8 \pm 0.2$ SDS $)$ and within the $\mathrm{TH}$ $(-1.2 \pm 0.2$ SDS $)$. Bone maturation was normal as documented by the BA/CA ratio. Serum IGF1 levels were also normal in children with SH $(-0.2 \pm 0.2$ SDS $)$ and comparable to those of the control group $(0.4 \pm 0.7$ SDS). As expected, SH children had TSH values

Table 1 Clinical and biochemical parameters of the children with $\mathrm{SH}$ and controls at study entry. Data are expressed as mean \pm S.E.M. Age ranges: SH children, 4.0-18.0 years; controls, 3.2-16.0 years. Reference ranges: TSH, 0.3-4.2 mU/l; $\mathrm{FT}_{4}, 9-26 \mathrm{pmol} / \mathrm{l} ; \mathrm{Tg}$, 0-50 ng/ml; urinary iodine excretion, 100-200 $\mu \mathrm{g} / \mathrm{l}$.

\begin{tabular}{lccl}
\hline & $\begin{array}{c}\text { SH } \\
(n=36)\end{array}$ & $\begin{array}{c}\text { Controls } \\
(n=36)\end{array}$ & $\boldsymbol{P}$ \\
\hline Age (year) & $9.7 \pm 0.6$ & $9.5 \pm 0.5$ & $\mathrm{NS}$ \\
Bone age (year) & $9.4 \pm 0.6$ & $9.2 \pm 0.8$ & $\mathrm{NS}$ \\
BA/CA & $0.97 \pm 0.1$ & $0.96 \pm 0.6$ & $\mathrm{NS}$ \\
Height (SDS) & $-0.8 \pm 0.2$ & $-0.6 \pm 0.2$ & $\mathrm{NS}$ \\
Target height (SDS) & $-1.2 \pm 0.2$ & $-0.5 \pm 0.1$ & $<0.003$ \\
Height velocity (SDS) & $-0.05 \pm 0.3$ & $-0.6 \pm 0.7$ & $\mathrm{NS}$ \\
Body mass index (SDS) & $-0.1 \pm 0.2$ & $-0.1 \pm 0.2$ & $\mathrm{NS}$ \\
IGF1 (SDS) & $-0.2 \pm 0.2$ & $0.4 \pm 0.7$ & $\mathrm{NS}$ \\
TSH (mU/l) & $6.4 \pm 0.3$ & $2.6 \pm 0.2$ & $<0.0001$ \\
FT 4 (pmol/I) & $18.0 \pm 1.3$ & $16.7 \pm 1.3$ & $\mathrm{NS}$ \\
Tg (ng/ml) & $23.0 \pm 1.9$ & $17.4 \pm 2.3$ & $\mathrm{NS}$ \\
Urinary iodine excretion & $142.0 \pm 15.6$ & $193.2 \pm 47.3$ & $\mathrm{NS}$ \\
$\quad(\mu g / l)$ & & & \\
\hline
\end{tabular}

NS, not significant. 
significantly higher than those of controls $(P<0.0001)$. BMI in SH children was comparable to that of the control group, and only $3 / 36$ of them $(8 \%)$ were obese (BMI >2 SDS). Despite normal mean height, a subgroup of eight SH children with short stature $(<-2$ SDS) was identified (Table 2). In six of them, height $(-2.4 \pm 0.2$ SDS $)$ was within the TH $(-2.3$ \pm 0.2 SDS), thus indicating a familial short stature, and two SH children had stature $(-2.4 \pm 0.4$ SDS $)$ below the TH $(-1.4 \pm 0.5$ SDS) with normal growth velocity $(-0.8 \pm 0.5$ SDS), normal serum IGF1 $(-0.1 \pm 1.2$ SDS), normal GH peak after stimulation test, and a delay of 2 years in bone maturation (BA/CA 0.8), suggesting a possible constitutional delay of growth and puberty (CDGP).

At enrollment in the study, the duration of $\mathrm{SH}$ in children was $3.3 \pm 0.3$ (range 2.0-9.3) years. During the period from the time of first SH detection until enrollment in the study, none of the SH children developed any overt clinical signs or symptoms of hypothyroidism such as fatigue, mood changes, impaired concentration, and goiter or showed alterations in both thyroid antibodies and thyroid ultrasound pattern. Moreover, no significant changes in height, bone maturation, IGF1 levels, BMI, TSH values, and thyroid hormone were observed in this period (Table 3). Also in the eight SH children having short stature, height, growth velocity, bone maturation, and IGF1 levels did not significantly change (Table 2).

In 9 (six females; $25 \%$ ) of the 36 children, puberty began and progressed normally despite long-term $\mathrm{SH}$ duration (2.2-7.5 years). Moreover, four of them (two females) achieved final height $(-0.4 \pm 0.7$ SDS $)$ that was more than adequate for the TH $(-1.4 \pm 0.6$ SDS).

\section{Intellectual outcome}

Of the 36 children with SH, 30 agreed to undergo intellectual evaluation. Mean verbal $(99.1 \pm 2.2)$,

Table 2 Clinical and biochemical parameters at the time of the first $\mathrm{SH}$ detection compared to those at the time of study entry in eight children with persistent $\mathrm{SH}$ and short stature ( $<-2 \mathrm{SDS}$ ). Data are expressed as mean \pm S.E.M. SH children age ranges: first detection of TSH increase, 3.0-11.5 years; study entry, 5.0-18.0 years. Reference ranges: TSH, 0.3-4.2 mU//; $\mathrm{FT}_{4}, 9-26 \mathrm{pmol} / \mathrm{l}$.

\begin{tabular}{lcrc}
\hline & $\begin{array}{l}\text { First SH } \\
\text { detection }(n=8)\end{array}$ & $\begin{array}{l}\text { Study } \\
\text { entry }(n=8)\end{array}$ & $\boldsymbol{P}$ \\
\hline Age (year) & $7.8 \pm 1.0$ & $10.8 \pm 1.5$ & $<0.02$ \\
$\mathrm{BA} / \mathrm{CA}$ & $0.9 \pm 0.1$ & $0.8 \pm 0.1$ & $\mathrm{NS}$ \\
Height (SDS) & $-2.4 \pm 0.1$ & $-2.4 \pm 0.2$ & $\mathrm{NS}$ \\
Target height (SDS) & $-2.3 \pm 0.2$ & $-2.3 \pm 0.2$ & $\mathrm{NS}$ \\
IGF1 (SDS) & $-0.7 \pm 0.5$ & $-0.7 \pm 0.3$ & $\mathrm{NS}$ \\
Height velocity (SDS) & $-0.1 \pm 0.8$ & $0.4 \pm 0.6$ & $\mathrm{NS}$ \\
$\mathrm{TSH}$ (mU/l) & $6.3 \pm 0.4$ & $7.6 \pm 0.8$ & $\mathrm{NS}$ \\
$\mathrm{FT}_{4}$ (pmol/l) & $23.2 \pm 3.9$ & $18.0 \pm 1.3$ & $\mathrm{NS}$ \\
\hline
\end{tabular}

NS, not significant.
Table 3 Clinical and biochemical parameters at the time of the first $\mathrm{SH}$ detection compared with those at study entry in children with persistent SH. Data are expressed as mean \pm S.E.M. SH children age ranges: first SH detection, 2.0-12.1 years; study entry, 4.018.0 years. Reference ranges: $\mathrm{TSH}, 0.3-4.2 \mathrm{mU} / \mathrm{l} ; \mathrm{FT}_{4}, 9-26 \mathrm{pmol} / \mathrm{l}$; Tg, 0-50 ng/ml; Tg-Ab, 0-115 IU/ml; TPO-Ab, 0-34 IU/ml; urinary iodine (I) excretion, $100-200 \mu \mathrm{g} / \mathrm{l}$.

\begin{tabular}{lccl}
\hline & $\begin{array}{c}\text { First SH } \\
\text { detection } \\
(n=36)\end{array}$ & $\begin{array}{c}\text { Study entry } \\
(n=36)\end{array}$ & $\boldsymbol{P}$ \\
\hline Age (year) & $6.4 \pm 0.5$ & $9.7 \pm 0.6$ & $<0.0001$ \\
Bone age (year) & $6.0 \pm 0.6$ & $9.4 \pm 0.6$ & $<0.0001$ \\
BA/CA & $0.92 \pm 0.03$ & $0.97 \pm 0.03$ & $\mathrm{NS}$ \\
Height (SDS) & $-0.7 \pm 0.2$ & $-0.8 \pm 0.2$ & $\mathrm{NS}$ \\
IGF1 (SDS) & $-0.4 \pm 0.3$ & $-0.2 \pm 0.2$ & $\mathrm{NS}$ \\
Body mass index (SDS) & $-0.1 \pm 0.2$ & $-0.1 \pm 0.2$ & $\mathrm{NS}$ \\
$\mathrm{TSH}$ (mU/l) & $6.4 \pm 0.2$ & $6.4 \pm 0.3$ & $\mathrm{NS}$ \\
$\mathrm{FT}$ ( (mmol/l) & $18.0 \pm 1.3$ & $18.0 \pm 1.3$ & $\mathrm{NS}$ \\
$\mathrm{Tg}(\mathrm{ng} / \mathrm{ml})$ & $23.3 \pm 2.2$ & $22.7 \pm 1.9$ & $\mathrm{NS}$ \\
$\mathrm{Tg}-\mathrm{Ab}(\mathrm{IU} / \mathrm{ml})$ & $15.3 \pm 1.0$ & $17.0 \pm 1.1$ & $\mathrm{NS}$ \\
$\mathrm{TPO}-\mathrm{Ab}(\mathrm{IU} / \mathrm{ml})$ & $8.9 \pm 0.8$ & $9.9 \pm 1.1$ & $\mathrm{NS}$ \\
Urinary l excretion $(\mu \mathrm{gg} / \mathrm{ll})$ & $192.2 \pm 26.6$ & $142.0 \pm 15.6$ & $\mathrm{NS}$ \\
\hline
\end{tabular}

NS, not significant.

performance (100.4 \pm 1.9$)$, and full-scale $(99.7 \pm 1.9)$ IQ scores were within normal range and comparable to IQ scores of the control group (Table 4). SES score was similar in SH children $(13.9 \pm 0.8)$ and controls

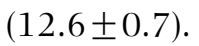

None of the SH children showed a subnormal IQ $(<80)$. However, 7 of the $30 \mathrm{SH}$ children $(23.3 \%)$ showed a low-normal verbal $(84.3 \pm 1.7)$, performance $(88.8 \pm 1.3)$, and full-scale $(85.3 \pm 0.9)$ IQ score. In these children, a higher SES score $(17.0 \pm 0.9)$, documenting a lower SES, was observed in comparison with the SES score $(13.4 \pm 0.7, P=0.005)$ of the remaining $23 \mathrm{SH}$ children having normal IQ (VIQ $103.9 \pm 2.2$, PIQ $102.8 \pm 2.1$, and FSIQ $104.5 \pm 2.2$ ). Furthermore, the IQ scores of these seven SH children were comparable to those of seven controls (VIQ 81.0 \pm 2.0 , PIQ 92.8 \pm 4.0 , and FSIQ 83.6 \pm 1.9 ) who also had a higher SES compared with the remaining 23 controls (16.9 \pm 0.8 vs $11.6 \pm 0.7, P<0.0004)$.

A significant negative correlation was observed between SES and verbal $(r=-0.69, P=0.0007)$, performance $(r=-0.61, P<0.005)$, and full-scale $(r=-0.52, P<0.009)$ IQ scores of all SH children.

Analysis of verbal and performance subtests did not reveal any difference between children with $\mathrm{SH}$ and controls (Fig. 1).

The results of the behavioral and psychological assessments are summarized in Fig. 2. The evaluation of neuropsychological function through the $\mathrm{CDI}$ and the CBCL did not show any significant difference between SH children and controls. Moreover, the proportion of SH children and controls having a borderline value at CBCL was similar (total problems 17 vs $21 \%$, internalizing 13 vs $10 \%$ and externalizing 10 vs $10 \%$ ). 
Table 4 Mean IQ scores of children with persistent SH compared with those of the control group. Data are expressed as mean \pm S.E.M. Age ranges: $\mathrm{SH}$ children, $4.0-16.0$ years; controls, $5.0-16.0$ years. Reference ranges: IQ scores, 80-115. Reference ranges: TSH, $0.3-4.2 \mathrm{mU} / \mathrm{l} ; \mathrm{FT}_{4}, 9-26 \mathrm{pmol} / \mathrm{l}$.

\begin{tabular}{lrrl}
\hline & $\begin{array}{c}\text { Persistent SH } \\
(n=30)\end{array}$ & $\begin{array}{c}\text { Controls } \\
(n=30)\end{array}$ & $\boldsymbol{P}$ \\
\hline Age (year) & $8.4 \pm 0.7$ & $9.1 \pm 0.6$ & $\mathrm{NS}$ \\
$\mathrm{TSH}(\mathrm{mU} / \mathrm{l})$ & $5.8 \pm 0.3$ & $2.5 \pm 0.3$ & $<0.0001$ \\
$\mathrm{FT}_{4}(\mathrm{pmol} / \mathrm{l})$ & $15.4 \pm 0.8$ & $15.7 \pm 0.3$ & $\mathrm{NS}$ \\
Verbal IQ & $99.1 \pm 2.2$ & $100.1 \pm 2.9$ & $\mathrm{NS}$ \\
Performance IQ & $100.4 \pm 1.9$ & $104.3 \pm 2.1$ & $\mathrm{NS}$ \\
Full scale IQ & $99.7 \pm 1.9$ & $101.6 \pm 2.4$ & $\mathrm{NS}$ \\
\hline
\end{tabular}

NS, not significant.

There was no relationship between mean TSH levels during the follow-up or the duration of $\mathrm{SH}$ and $\mathrm{IQ}$ scores, IQ subtests, CBCL and CDI scores.

\section{Discussion}

SH is defined as a serum TSH concentration above the upper limit of the reference range when serum $\mathrm{FT}_{4}$ concentration is within its reference range (2). This biochemical condition could be expected just on statistical grounds to be found in around $2.3 \%$ of the general population, but this does not mean that $2.3 \%$ has some type of hypothyroidism. According to the only recent epidemiological study concerning pediatric age, it may be found in $1.7 \%$ adolescents (9). We have no epidemiological data about the prevalence of SH in our regions, but it is to be considered that the one recruited for this study was a population including only subjects with a condition of persistent SH lasting for at least 2 years preceding this investigation.

The management of children with $\mathrm{SH}$ is a controversial issue. Whether this biochemical condition is associated with clinical and neuropsychological abnormalities is still debated, and the benefits of $\mathrm{L}-\mathrm{T}_{4}$ treatment in these subjects have not yet been demonstrated (16).

There are few studies in the literature on pediatric SH. Wasniewska et al. (11) have recently investigated the natural course of persistent SH in a large pediatric population. During a 2-year follow-up, no significant changes were observed in linear and ponderal growth. Moreover, $41 \%$ of children normalized their serum TSH spontaneously. This percentage is slightly higher than that observed in our study $(23 \%)$, but the difference might be due to the lower number of children and of centers participating in this study.

Our current study is the first controlled study that evaluates the long-term effects of persistent SH on children's growth and cognitive functions.

Auxological parameters were not affected in the majority of our children even after a period of 2.0-9.3 years of persistent SH. Although short stature was observed in about $22 \%$ of our SH children a diagnosis of familial short stature and/or CDGP was made in all of them.

Thyroid hormone can influence growth either by a direct action on the bone or by altering the secretion and action of $\mathrm{GH}$ and ultimately by influencing the synthesis and secretion of IGF1. Several studies have reported a reduction in IGF1 levels in adults with overt and SH (17). Recently, Akim et al. (18) reported low serum IGF1 levels in adults with SH, compared to euthyroid subjects, which significantly increased after normalization of thyroid function with $\mathrm{L}-\mathrm{T}_{4}$ therapy. In our children, serum IGF1 concentrations at study entry were slightly lower than those found in the control group, but the difference was not statistically significant. Compared with IGF1 values at the time of the first SH detection, we did not observe any significant change or worsening in the serum IGF1 levels of children despite persistent SH. In short children with $\mathrm{SH}$, the evaluation of $\mathrm{GH}$ secretion after the stimulation test did not identify any abnormalities in the GH-IGF1

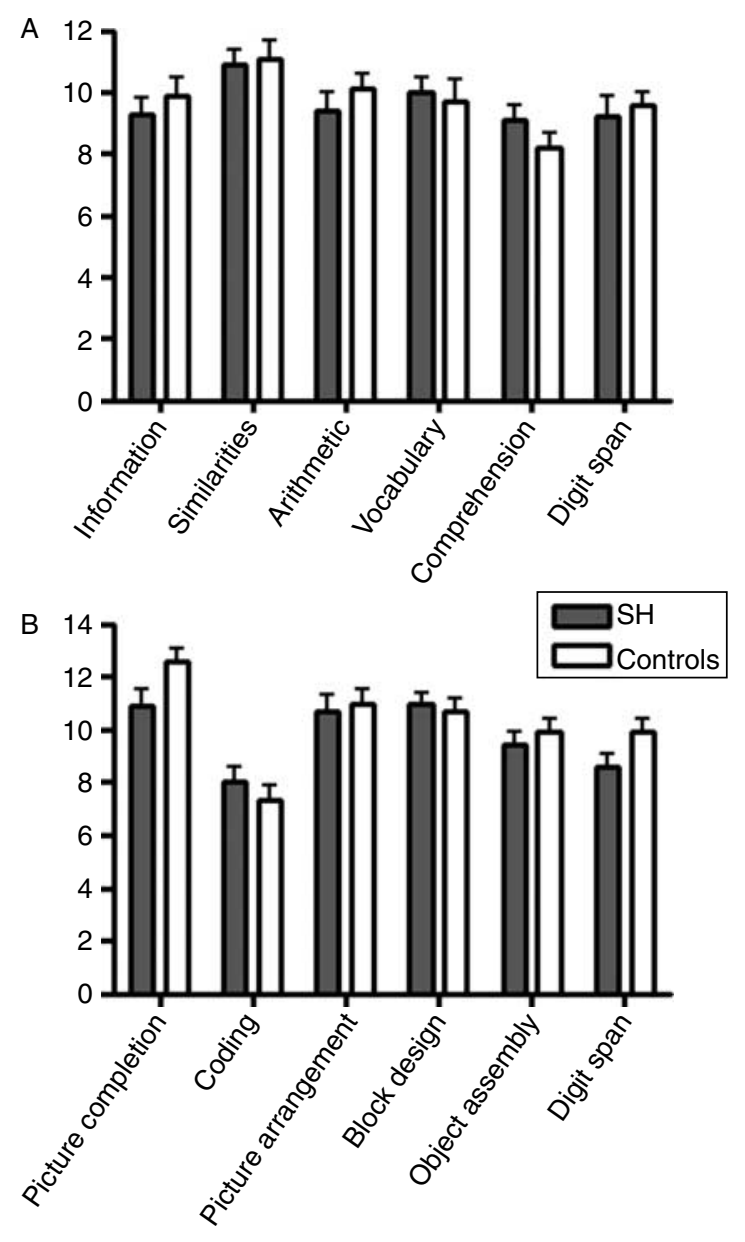

Figure 1 Verbal (A) and performance (B) subtests score of children with persistent $\mathrm{SH}$ (aged 4-16 years) compared with the control group (aged 5-16 years). 

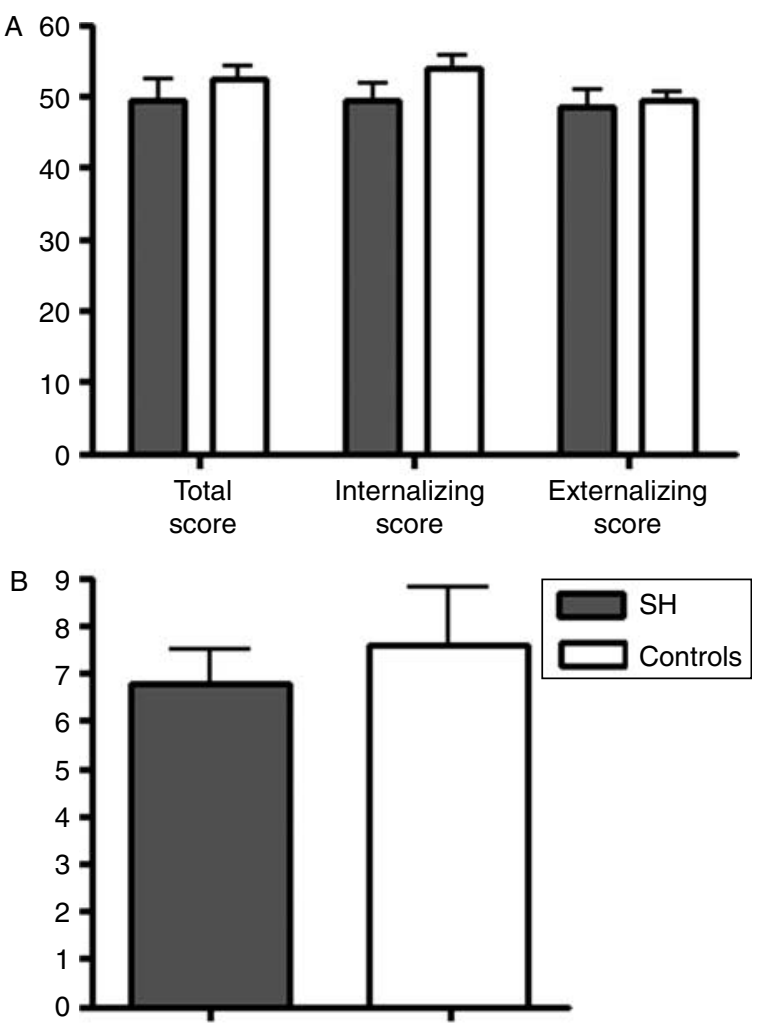

Figure 2 Psychological and behavioral rating at $\mathrm{CBCL}(\mathrm{A})$ and $\mathrm{CDI}(\mathrm{B})$ in children with persistent $\mathrm{SH}$ (aged 4-16 years) compared with the control group (aged 5-16 years).

axis. Moreover, we did not find any association between stature and the degree or duration of $\mathrm{SH}$.

Overall, these results are in agreement with the previous findings of normal growth in children with idiopathic SH (11) and with data from Radetti et al. (10) suggesting that growth is not affected even after many years of untreated autoimmune SH.

Only one study has evaluated the response to $\mathrm{L}-\mathrm{T}_{4}$ treatment on growth in children with SH (19). In both pre-pubertal and pubertal children with $\mathrm{SH}$, 6 months to 1 year of treatment with $\mathrm{L}^{-} \mathrm{T}_{4}$ seemed to significantly improve growth velocity. However, that study had several limitations such as i) an arbitrary definition of SH (an exaggerated response to TRH stimulus test), ii) patients were enrolled from a group of children with short stature, and iii) mean BA maturation was delayed, thus suggesting a CDGP that may itself be associated with a spontaneous improvement in stature over time.

The relationship between obesity and thyroid function in children is still being debated. Overt and SH are often associated with an increase in weight, but an increase in TSH levels is a common finding in obese children. However, substantial weight loss induces a normalization of thyroid function in children and adults, thus suggesting that the increase in TSH could reflect an adaptation process of the hypothalamus-pituitarythyroid axis to obesity, and, therefore, treatment with $\mathrm{L}-\mathrm{T}_{4}$ seems unnecessary in these children $(20,21)$. In our study, the percentage of obese children $(8 \%)$ was lower than in other studies $(11,22)$, and this may depend on the different inclusion and exclusion criteria. However, in accordance with the previous study by Wasniewska et al. (11), we did not observe any significant change in the BMI even after several years of persistent SH. Moreover, we did not find any association between the degree of obesity and the severity or duration of SH.

Thyroid hormone is essential for the development of the $\mathrm{CN}$ as documented by the significant long-term effect that thyroid hormone replacement therapy has on neurodevelopmental and motor outcomes in children with congenital hypothyroidism (12).

In adults, thyroid hormone may influence memory and mood. Several studies have evaluated the quality of life and cognitive function in adults with $\mathrm{SH}$, yielding conflicting results. To further complicate this issue, a systematic review on the effects of $\mathrm{L}-\mathrm{T}_{4}$ therapy in $\mathrm{SH}$ and in particular on health-related quality of life and neuropsychological symptoms failed to demonstrate any significant improvement in treated subjects (16).

To date, few studies have examined neurocognitive function in children with SH. In the study by Wu et al. (9), cognitive function was evaluated in 1.327 children, aged 12-16 years, who participated in the Third National Health and Nutrition Examination Survey. Cognitive assessment scores were on average higher in adolescents with SH than in the euthyroid group, thus suggesting that occasionally elevated TSH levels do not impair cognitive function. In a small short-term study by Aijaz et al. (23), L- $\mathrm{T}_{4}$ therapy was unable to improve neuropsychological function in 11 SH children having attention problems compared with normal standards.

Overall, in our children, the evaluation of cognitive aspects did not reveal alteration in the total, verbal, or PIQ even after several years of persistent SH. We were able to identify a subgroup of children with SH (23\%) who performed significantly worse in both verbal and performance area compared with the remaining $\mathrm{SH}$ children. However, we did not find any relationship between the IQ scores and the degree or duration of SH. As expected, a significant association was observed with SES scores, suggesting that the educational level and occupational background of the parents may significantly influence cognitive functioning more than slightly elevated TSH levels.

The evaluation of neuropsychological function through the CDI and the CBCL, which rate behavior and emotional problems both globally and along two dimensions of internalizing symptoms (anxiety and depression) and externalizing symptoms (aggression and hyperactivity) did not reveal any significant difference between children with SH and controls.

In conclusion, our data indicate that persistent SH in children and adolescents does not affect growth, bone 
maturation, BMI, and cognitive functions. Studies on a larger number of children are needed to further clarify whether SH in childhood is associated with relevant abnormalities that may require $\mathrm{L}_{-} \mathrm{T}_{4}$ treatment. In the meantime, a therapeutic trial with $\mathrm{L}-\mathrm{T}_{4}$ might be taken into consideration only in children with complaints that can be ascribed to thyroid dysfunction, whereas those without any complaint should not be exposed to drugs.

\section{Declaration of interest}

The authors declare that there is no conflict of interest that could be perceived as prejudicing the impartiality of the research reported.

\section{Funding}

This research did not receive any specific grant from any funding agency in the public, commercial, or not-for-profit sector.

\section{References}

1 Biondi B \& Cooper DS. The clinical significance of subclinical thyroid disfunction. Endocrine Reviews 200829 76-131. (doi:10. 1210/er.2006-0043)

2 Surks MI, Ortiz E, Daniels GH, Sawin CT, Col NF, Cobin RH, Franklyn JA, Hershman JM, Burman KD, Denke MA, Gorman C, Cooper RS \& Weissman NJ. Subclinical thyroid disease: scientific review and guidelines for diagnosis and management. Journal of the American Medical Association 2004291 228-238. (doi:10. 1001/jama.291.2.228)

3 Gharib H, Tuttle RM, Baskin HJ, Fish LH, Singer PA \& McDermott MT. Subclinical thyroid disfunction: a joint statement of management from the American Association of Clinical Endocrinologists, the American Thyroid Association, and the Endocrine Society. Journal of Clinical Endocrinology and Metabolism 200590 581-585. (doi:10.1210/jc.2004-1231)

4 Canaris GJ, Manowitz NR, Mayor G \& Ridgway EC. The colorado thyroid disease prevalence study. Archives of Internal Medicine 2000 160 526-534. (doi:10.1001/archinte.160.4.526)

5 Danese MD, Ladenson PW, Meinert CL \& Powe NR. Clinical review 115: effect of thyroxine therapy on serum lipoproteins in patients with mild thyroid failure: a quantitative review of the literature. Journal of Clinical Endocrinology and Metabolism $2000 \mathbf{8 5}$ 2993-3001. (doi:10.1210/jc.85.9.2993)

6 Ochs N, Auer R, Bauer DC, Nanchen D, Gussekloo J, Cornuz J \& Rodondi N. Meta-analysis: subclinical thyroid dysfunction and the risk for coronary heart disease and mortality. Annals of Internal Medicine 2008148 832-845.

7 Monzani F, Del Guerra P, Caraccio N, Pruneti CA, Pucci E, Luisi M \& Baschieri L. Subclinical hypothyroidism: neurobehavioral features and beneficial effect of L-thyroxine treatment. Clinical Investigator 199371 367-371. (doi:10.1007/BF00186625)

8 Baldini IM, Vita A, Maura MC, Amodei V, Carrisi M, Bravin S \& Cantalamessa L. Psychopathological and cognitive features in subclinical hypothyroidism. Progress in Neuro-Psychopharmacology $\mathcal{E}$ Biological Psychiatry 199721 925-935. (doi:10.1016/S02785846(97)00089-4)

$9 \mathrm{Wu}$ T, Flowers JW, Tudiver F, Wilson JL \& Punyasavatsut N. Subclinical thyroid disorders and cognitive performance among adolescents in the United States. BMC Pediatrics 2006612. (doi:10.1186/1471-2431-6-12)
10 Radetti G, Gottardi E, Bona G, Corrias A, Salardi A \& Loche S. Study group for thyroid diseases of the Italian Society for Pediatric Endocrinology and Diabetes (SIEDP/ISPED). The natural history of euthyroid Hashimoto's thyroiditis in children. Journal of Pediatrics 2006149 827-832. (doi:10.1016/j.jpeds.2006.08.045)

11 Wasniewska M, Salerno M, Cassio A, Corrias A, Aversa T, Zirilli G, Capalbo D, Bal M, Mussa A \& De Luca F. Prospective evaluation of the natural course of idiopathic subclinical hypothyroidism in childhood and adolescence. European Journal of Endocrinology 2009160 417-421. (doi:10.1530/EJE-08-0625)

12 Salerno M, Militerni R, Di Maio S, Bravaccio C, Gasparini N \& Tenore A. Intellectual outcome at 12 years of age in congenital hypothyroidism. European Journal of Endocrinology 1999141 105-110. (doi:10.1530/eje.0.1410105)

13 Greulich WW \& Pyle SI. Radiographic Atlas of Skeletal Development of the Hand and Wrist, 2nd edn. Standford, CA, USA: Standford University Press, 1959.

14 Tanner JM, Whitehouse RH \& Takaishi M. Standards from birth to maturity for height, weight, height velocity and weight velocity: British children, 1965. Archives of Disease in Childhood 196641 613-635. (doi:10.1136/adc.41.220.613)

15 Cacciari E, Milani S \& Balsamo A. Directive councils of SIEDP/ISPED for 1996-97 and 2002-03. Italian cross-sectional growth charts for height weight and BMI ( 2 to $20 \mathrm{yr}$ ). Journal of Endocrinological Investigation 200629 581-593.

16 Villar HCCE, Saconato H, Valente O \& Atallah AN. Thyroid hormone replacement for subclinical hypothyroidism. Cochrane Database of Systematic Reviews 200718 CD003419. (doi:10. 1002/14651858.CD003419.pub2)

17 Akin F, Yaylali GF, Turgut S \& Kaptanoglu B. Growth hormone/insulin-like growth factor axis in patients with subclinical thyroid dysfunction. Growth Hormone and IGF Research 200919 252-255. (doi:10.1016/j.ghir.2008.11.003)

18 Akin F, Bastemir M, Yaylali GF, Alkis F \& Kaptanoglu B. GH/IGF-1 axis in patients with subclinical hypothyroidism. Clinical Endocrinology 200868 1009-1010. (doi:10.1111/j.1365-2265. 2007.03134.x)

19 Cetinkaya E, Aslan AT, Vidinlisan S \& Ocal G. Height improvement by L-thyroxine treatment in subclinical hypothyroidism. Pediatrics International $2003 \mathbf{4 5}$ 534-537. (doi:10.1046/j.1442-200X. 2003.01786.x)

20 Reinehr T, De Sousa G \& Andler W. Hyperthyrotropinemia in obese children is reversible after weight loss and is not related to lipids. Journal of Clinical Endocrinology and Metabolism 200691 3088-3091. (doi:10.1210/jc.2006-0095)

21 Marras V, Casini MR, Pilia S, Carta D, Civolani P, Porcu M, Uccheddu AP \& Loche S. Thyroid function in obese children and adolescents. Hormone Research in Pediatrics 201073 193-197. (doi:10.1159/000284361)

22 Rapa A, Monzani A, Moia A, Vivenza D, Bellone S, Petri A, Teofoli F, Cassio A, Cesaretti G, Corrias A, de Sanctis V, Di Maio S, Volta C, Wasniewska M, Tatò L \& Bona G. Subclinical hypothyroidism in children and adolescents: a wide range of clinical, biochemical and genetic factors involved. Journal of Clinical Endocrinology and Metabolism 200994 2414-2420. (doi:10.1210/jc.2009-0375)

23 Aijaz NJ, Flaherty EM, Preston T, Bracken SS, Lane AH \& Wilson TA. Neurocognitive function in children with compensated hypothyroidism: lack of short term effects on or off thyroxine. BMC Pediatrics 20066 2. (doi:10.1186/1471-2431-6-2)

Received 27 January 2011

Accepted 3 February 2011 